\title{
EXSUdAÇÃo RAdiculaR do GLYPHOSATE POR Brachiaria decumbens E Seus Efeitos em Plantas de Eucalipto e na Respiração MICROBIANA DO SOLO ${ }^{1}$
}

\author{
Root Exudation of Glyphosate by Brachiaria decumbens and its Effects on Eucalypt Plants and \\ Microbial Soil Respiration
}

\author{
TUFFI SANTOS, L.D. ${ }^{2}$, FERREIRA, F.A. ${ }^{3}$, BARROS, N.F. ${ }^{3}$, SIQUEIRA, C.H. ${ }^{4}$, SANTOS, I.C. ${ }^{5}$ e \\ MACHADO, A.F.L. ${ }^{6}$
}

\begin{abstract}
RESUMO - Este trabalho teve como objetivos: avaliar a exsudação radicular por Brachiaria decumbens e seus efeitos sobre plantas de eucalipto cultivadas em solo e em solução nutritiva; e quantificar a respiração microbiana no solo em diferentes manejos com o herbicida glyphosate. Vasos com 8,0 L de solução nutritiva, contendo cinco perfurações na tampa, receberam uma muda de Eucalyptus grandis e quatro mudas de Brachiaria decumbens. Utilizou-se o delineamento em blocos casualizados com seis repetições, sendo cada vaso considerado como parcela experimental. As plantas de eucalipto e braquiária permaneceram em consórcio na solução hidropônica por 30 dias, sendo as plantas de braquiária podadas aos 15 dias após o transplante, visando estimular o perfilhamento. Após esse período foram aplicados os tratamentos correspondentes a $0,720,1.440,2.160$ e $2.880 \mathrm{~g} \mathrm{e.a.} \mathrm{ha}{ }^{-1}$ de glyphosate sobre as plantas de braquiária. No experimento em solo, mudas de E. grandis foram plantadas em 72 vasos de $10 \mathrm{~L}, 36$ contendo solo arenoso e 36 solo argiloso. O delineamento experimental utilizado foi o de blocos casualizados com seis repetições, montado em esquema fatorial 2 x 6 (dois tipos de solo e seis combinações de manejo). Após o plantio das mudas de eucalipto, 48 vasos (24 de cada solo) receberam cinco mudas por vaso de Brachiaria decumbens, sendo estas cultivadas em consórcio com a muda de eucalipto. O restante dos vasos de eucalipto foi cultivado em monocultivo. Os tratamentos testados foram: 1 - eucalipto consorciado com braquiária (testemunha); 2 - eucalipto sem braquiária + 1.440 g e.a. ha ${ }^{-1}$ de glyphosate aplicado no solo; 3- eucalipto com braquiária cortada após pulverização com 1.440 g e.a. ha ${ }^{-1}$ de glyphosate; 4, 5 e 6 - eucalipto consorciado com braquiária pulverizada respectivamente com 720, 1.440 e 2.880 g e.a. ha-1 de glyphosate. A aplicação foi feita sobre as plantas de braquiária nos tratamentos 4, 5 e 6, protegendo a planta de eucalipto do contato com o herbicida. O tratamento 2 recebeu a aplicação do glyphosate diretamente no solo. No tratamento 3, os vasos de eucalipto receberam a parte aérea de plantas de braquiária cortadas, sete dias após estas terem sido pulverizadas com 1.440 g e.a. ha ${ }^{-1}$ de glyphosate. Nos dois ensaios houve controle acima de 95\% da gramínea por todas as doses testadas, não sendo verificados sintomas de toxidez nas plantas de eucalipto. A atividade microbiana foi maior no solo arenoso, principalmente com o aumento das doses de glyphosate aplicadas nas plantas de braquiária.
\end{abstract}

Palavras-chave: herbicida, Eucalyptus spp., atividade microbiana, biodegradação.

ABSTRACT - This study aimed to evaluate root exudation of the herbicide glyphosate by Brachiaria decumbens and its effects on eucalypt cultivated in soil and in nutritive solution; and to quantify microbial respiration in soil under different managements. One Eucalyptus grandis and four

1 Recebido para publicação em 30.8.2004 e na forma revisada em 21.4.2005.

Parte da dissertação de mestrado do primeiro autor (Bolsista do CNPq).

2 Doutorando em Fitotecnia, Departamento de Fitotecnia da Universidade Federal de Viçosa - DFT/UFV, 36570-000 Viçosa-MG, $<$ ltuffi@yahoo.com.br>; ${ }^{3}$ Professor Titular da UFV; ${ }^{4}$ Engenheiro-agrônomo; ${ }^{5}$ Pesquisadora, EPAMIG/CTZM. ${ }^{6}$ Mestrando em Fitotecnia - DFT/UFV. 
Brachiaria decumbens seedlings were planted in pots with lids with five perforations holding 8.0 L of the nutritive solution. A randomized block design in six replications was used, each pot being considered an experimental plot. The eucalypt and brachiaria plants were interplanted in a hydroponic solution for 30 days. Fifteen days after the transplant, the brachiaria plants were pruned to stimulate tillering. After this period, glyphosate treatments of $0,720,1440,2160$, and $2880 \mathrm{~g}$ a.e. $\mathrm{ha}^{-1}$ were applied to the brachiaria plants. In the soil experiment, $\boldsymbol{E}$. grandis seedlings were planted in 72 10-liter pots, half containing sandy soil and half clayey soil. The experiment was set up in a randomized block design with six replications, in a $2 \times 6$ factorial scheme (two soil types and six management combinations). Following the eucalypt seedlings, five Brachiaria decumbens seedlings per pot were planted in 48 pots (24 of each soil), and interplanted with a eucalypt seedling. The remaining eucalypt pots were cultivated in monoculture. The tested treatments were: 1- interplanted eucalypt and brachiaria (control); 2- Eucalypt without brachiaria + $1440 \mathrm{~g}$ a.e. $\mathrm{ha}^{-1}$ of glyphosate applied in the soil; 3-interplanted eucalypt and brachiaria cut after spray with $1440 \mathrm{~g} \mathrm{ha}^{-1}$ glyphosate; 4, 5 and 6-interplanted eucalypt and sprayed brachiaria with 720, 1440, and $2880 \mathrm{~g}$ a.e ha $\mathrm{a}^{-1}$ glyphosate, respectively. In treatments 4, 5, and 6 the eucalypt plants were protected from contact with the herbicide applied to the brachiaria plants. In treatment 2, glyphosate was applied directly to soil. The eucalypt plants in treatment 3 were treated with the brachiaria plant cut shoots, seven days after the latter had been sprayed with $1440 \mathrm{~g} \mathrm{ha}^{-1}$ glyphosate. All the tested rates controlled over 95\% of the grass species in both assays, and no toxicity symptoms were verified in the eucalypt plants. The microbial activity was greater in the sandy soil, mainly with the increase of the glyphosate rates applied to the brachiaria plants.

Key words: herbicide, Eucalyptus spp., microbial activity, biodegradation.

\section{INTRODUÇÃO}

O Brasil vem se tornando grande exportador de produtos florestais, o que se deve à melhoria tecnológica nas diversas partes da cadeia desse agronegócio e ao aprimoramento de práticas silviculturais, entre elas o manejo de plantas daninhas.

Em florestas de eucalipto, a interferência por plantas daninhas deve-se principalmente à competição por recursos do meio, sendo mais expressiva no primeiro ano de implantação da cultura. O setor florestal tem se expandido em áreas anteriormente ocupadas com pastagem, especialmente Brachiaria decumbens e Panicum maximum.

Nas empresas florestais há predomínio do uso da capina química, e o herbicida glyphosate se destaca por exercer efetivo controle sobre um grande número de espécies daninhas (Toledo et al., 2003). Trata-se de um herbicida sistêmico, não-seletivo e altamente solúvel em água. Seu mecanismo de ação baseia-se na interrupção da rota do ácido chiquímico, responsável pela produção dos aminoácidos aromáticos fenilalanina, tirosina e triptofano, essenciais para a sintese protéica e divisão celular em regiões meristemáticas da planta (Cole et al., 1983). Uma das vantagens deste herbicida é sua baixa toxicidade a mamíferos e à vida aquática, sendo, ainda, um produto rapidamente inativado no solo (Rodrigues \& Almeida, 1998).

Entretanto, existe preocupação quanto às doses utilizadas e ao destino final da molécula, pois o glyphosate pode não ficar restrito às plantas daninhas, sendo metabolizado a compostos não-tóxicos e/ou exsudado no solo e inativado (Sprankle et al., 1975; Rodrigues \& Almeida, 1998). Linder et al. (1964) verificaram que algumas plantas são capazes de exsudar no solo substâncias aplicadas via parte aérea. Segundo Smith (1976), a exsudação de compostos pelas raízes das plantas pode alterar o "pool" de nutrientes e outros compostos no solo, podendo representar significativas mudanças no sistema. Além disso, a liberação dessas substâncias pode ser fator inibitório para o desenvolvimento de plantas vizinhas (Linder et al., 1957).

Alguns herbicidas também são capazes de ser exsudados pelo sistema radicular de plantas daninhas e de culturas agrícolas, como o nicosulfuron (Gubbiga et al., 1996), o 2,4-D (Fites et al., 1964), o glyphosate (Coupland \& Caseley, 1979) e o imazapyr (Silva et al., 2004). 
Na cultura do eucalipto, o glyphosate é utilizado para o controle de plantas daninhas nas entrelinhas, podendo entrar em contato com ela via deriva. Existe ainda a possibilidade de contato via exsudação radicular pelas plantas daninhas tratadas. No campo, é difícil determinar a maneira como o glyphosate entra em contato com as plantas de eucalipto, porém seus efeitos sobre a cultura são visíveis. Uma vez em contato com o eucalipto, o glyphosate pode causar danos diretos, ou indiretos, como aumentar a suscetibilidade a doenças. Segundo Rizzardi et al. (2003), alguns dos efeitos dos herbicidas podem interferir nas reações das plantas ao ataque de patógenos; essa interferência pode ser quanto à severidade da doença ou na indução à síntese de fitoalexinas.

O glyphosate em contato com o solo via pulverização ou exsudado pelas plantas daninhas pode ser adsorvido às partículas de solo, biodegradado pelos microrganismos do solo (Rodrigues \& Almeida, 1998; Rueppel et al., 1977) ou absorvido pelas raizes do eucalipto, principalmente aquelas muito próximas a raízes de plantas daninhas tratadas com o herbicida.

Os microrganismos têm papel fundamental no comportamento dos herbicidas no ambiente, pois possuem a capacidade de metabolizar esses compostos, através de suas enzimas, e transformá-los em energia e nutrientes para a sua sobrevivência. A taxa de degradação de pesticidas é influenciada pela biomassa microbiana ativa e disponibilidade do composto para a biodegradação (Beigel et al., 1999), sendo a degradação conhecida como a transformação desses produtos em compostos menos tóxicos, $\mathrm{CO}_{2}$ e água. A degradação microbiana do glyphosate leva à formação do seu principal metabólito, o ácido aminometilfosfônico (AMPA), e, finalmente, $\mathrm{CO}_{2}$ (Rodrigues \& Almeida, 1998). Os efeitos adversos decorrentes da aplicação de herbicidas podem ocorrer na comunidade biótica do solo, com prejuízos aos microrganismos benéficos, ou podem ocasionar desequilíbrios em processos bioquímicos, como decomposição da matéria orgânica e ciclagem de nutrientes (Ghini et al., 1997).

A quantidade de $\mathrm{CO}_{2}$ desprendida do solo, determinada por métodos respirométricos, tem sido usada para estimação da atividade microbiana no solo, do tamanho da biomassa e do metabolismo do carbono disponivel no solo.

Diante da importância e dos riscos do uso do glyphosate nos agrossistemas florestais, o presente trabalho teve como objetivo avaliar a possivel exsudação radicular deste herbicida por Brachiaria decumbens e seus efeitos em plantas de eucalipto cultivadas em solo e em solução nutritiva, bem como quantificar a respiração microbiana em diferentes manejos com o glyphosate.

\section{MATERIAL E MÉTODOS}

Os experimentos foram conduzidos em casa de vegetação do Departamento de Fitotecnia da Universidade Federal de Viçosa, Viçosa-MG.

\section{Ensaio em solução nutritiva}

O ensaio em solução nutritiva foi realizado entre os meses de fevereiro e abril de 2004, utilizando-se a solução de Clark (Clark, 1975) modificada.

Foram utilizadas mudas de Eucalyptus grandis com aproximadamente dois meses de idade e $12 \mathrm{~cm}$ de altura, cultivadas em sacolas plásticas contendo solo argiloso, cedidas pelo Instituto Estadual de Florestas (IEF). Plantas de braquiária (Brachiaria decumbens) foram cultivadas em caixas de isopor com células contendo substrato orgânico, até atingirem $10 \mathrm{~cm}$ de altura. Após esse período as mudas de braquiária e de eucalipto tiveram seu sistema radicular lavado cuidadosamente, visando retirar todo o substrato. Posteriormente à lavagem, as mudas foram aclimatadas, durante uma semana, em bandejas de polietileno com capacidade para $30 \mathrm{~L}$, contendo a solução proposta a $50 \%$ de sua concentração.

Após aclimatação, as mudas foram transferidas para vasos plásticos com 8,0 L de solução, com tampas contendo cinco perfurações de $2,0 \mathrm{~cm}$ e uma de $1,0 \mathrm{~cm}$ de diâmetro. Nas perfurações de $2,0 \mathrm{~cm}$ foram colocadas uma muda de eucalipto e quatro de braquiária. A perfuração menor foi destinada ao tubo de arejamento da solução. O volume da solução dos vasos foi completado diariamente com água desionizada e o $\mathrm{pH}$ ajustado para 5,8 $\pm 0,3 \mathrm{com}$

Planta Daninha, Viçosa-MG, v. 23, n. 1, p. 143-152, 2005 
$\mathrm{NaOH}$ ou $\mathrm{HCl}$. As trocas da solução nutritiva foram efetuadas quando a condutividade elétrica da solução era reduzida em $30 \%$ em relação ao seu valor original.

O delineamento experimental utilizado foi o de blocos casualizados com seis repetições, e cada vaso foi considerado uma parcela experimental. As plantas de eucalipto e braquiária permaneceram em consórcio na solução hidropônica por 30 dias, sendo as de braquiária podadas aos 15 dias após o transplantio, visando estimular o perfilhamento. Após esse período, as plantas de braquiária apresentavam, em média, $2.842,24 \mathrm{~cm}^{2}$ de índice de área foliar e $12,25 \mathrm{~cm}^{3}$ de volume radicular por planta, e as mudas de eucalipto, $4,5 \mathrm{~cm}^{3}$ de volume de raiz e cerca de $30 \mathrm{~cm}$ de altura. Nessa época foram aplicados os tratamentos correspondentes a $0,720,1.440,2.160$ e 2.880 g e.a. ha ${ }^{-1}$ de glyphosate na forma do sal de isopropilamina. A aplicação foi realizada sobre as plantas de braquiária, utilizando pulverizador costal de precisão, propelido a gás carbônico, munido de barra com dois bicos tipo leque TT110.02, operando a $250 \mathrm{KPa}$ de pressão e volume de calda correspondente a $200 \mathrm{~L} \mathrm{ha}^{-1}$. No momento da aplicação, as mudas de eucalipto e o recipiente com a solução nutritiva foram totalmente protegidos com plástico, evitando, assim, o contato com a calda herbicida pulverizada. Após a aplicação do glyphosate, a parte aérea das mudas de eucalipto permaneceu por 10 horas isolada da parte aérea das plantas de braquiária, por meio de uma tela de náilon branca. A partir dessa época não mais se efetuou a troca da solução nutritiva, completando apenas o volume com água e ajustando-se o $\mathrm{pH}$.

Aos 7 e 14 dias após a aplicação (DAA) do glyphosate foi feita avaliação visual da porcentagem de controle em relação à testemunha, em que $0 \%$ corresponde à ausência de sintomas visiveis e $100 \%$ à morte das plantas de braquiária.
Para comprovação da exsudação radicular do glyphosate pelas plantas de braquiária pulverizadas, foi avaliada a intoxicação do eucalipto após a aplicação do herbicida na braquiária, em que $0 \%$ representa a ausência de sintomas e $100 \%$ a morte das plantas.

Avaliações referentes a altura das plantas (região entre o coleto e o ápice da planta), diâmetro do caule a $1 \mathrm{~cm}$ do coleto e biomassa seca da parte aérea e raiz foram realizadas aos 28 DAA, sendo os dados submetidos à análise estatística.

\section{Ensaio no solo}

O ensaio foi realizado entre os meses de fevereiro e abril de 2004, utilizando-se mudas de Eucalyptus urophylla $\mathrm{x}$ E. grandis (Clone 1213 da CENIBRA), com aproximadamente três meses de idade, cultivadas em tubetes de polipropileno de $55 \mathrm{~cm}^{3}$ de capacidade, com substrato composto de vermiculita e casca de arroz carbonizada. As mudas foram plantadas em 72 vasos de 10 L, 36 contendo solo francoargilo-arenoso e 36 solo argiloso, cujas características físicas e químicas estão apresentadas na Tabela 1 . O solo de cada vaso recebeu 216,6 g da formulação 6-30-6 (N-P-K) e 12 g de calcário, com relação $\mathrm{Ca}: \mathrm{Mg}=4: 1$ equivalentes. Durante o crescimento das mudas, efetuaram-se duas adubações de cobertura, aplicando-se $6 \mathrm{~g}$ por vaso da formulação 20-5-20 (N-P-K). Simultaneamente ao plantio das mudas de eucalipto, foram semeados 10 vasos (cinco para cada tipo de solo) com Brachiaria decumbens, de forma que fossem obtidas cinco plantas por vaso após o desbaste.

Após o plantio das mudas de eucalipto, 48 vasos (24 de cada solo) receberam o transplante de cinco mudas por vaso de Brachiaria decumbens, com aproximadamente $10 \mathrm{~cm}$ de altura, previamente cultivadas em bandejas de polipropileno com substrato de vermiculita e casca de arroz carbonizada. As plantas de

Tabela 1 - Características físicas e químicas dos solos usados para o plantio do eucalipto

\begin{tabular}{|c|c|c|c|c|c|c|c|c|}
\hline \multirow{2}{*}{ Classe textural dos solos } & Areia & Silte & Argila & \multirow{2}{*}{$\begin{array}{c}\mathrm{pH} \\
\left(\mathrm{H}_{2} \mathrm{O}\right)\end{array}$} & $\mathrm{MO}$ & $\mathrm{H}+\mathrm{Al}$ & $\mathrm{T}$ & \multirow{2}{*}{$\begin{array}{c}\mathrm{V} \\
(\%)\end{array}$} \\
\hline & \multicolumn{3}{|c|}{$\left(\right.$ dag kg $\left.{ }^{-1}\right)$} & & $\left(\right.$ dag kg $\left.^{-1}\right)$ & \multicolumn{2}{|c|}{$\left(\mathrm{cmol}_{\mathrm{c}} \mathrm{dm}^{-3}\right)$} & \\
\hline Franco-argilo-arenoso & 75 & 4 & 21 & 6,12 & 1,38 & 2,3 & 4,40 & 47,8 \\
\hline Argiloso & 38 & 10 & 52 & 5,73 & 2,76 & 3,6 & 7,00 & 48,6 \\
\hline
\end{tabular}


braquiária foram cultivadas em consórcio com a muda de eucalipto, procedendo-se duas podas aos $20 \mathrm{~cm}$ de altura das plantas de braquiária, aos 15 e 30 dias após o transplantio, visando o perfilhamento da graminea. Os outros 24 vasos permaneceram com mudas de eucalipto em monocultivo.

O delineamento experimental foi o de blocos casualizados com seis repetições, sendo cada vaso considerado uma parcela experimental. Os tratamentos foram dispostos em esquema fatorial $2 \times 6$ (dois tipos de solo e seis combinações eucalipto - braquiária glyphosate).

Os tratamentos testados foram: 1 - eucalipto consorciado com braquiária (testemunha); 2 - eucalipto sem braquiária e com $1.440 \mathrm{~g} \mathrm{ha}^{-1}$ de glyphosate aplicado no solo; 3 eucalipto com braquiária cortada pulverizada com $1.440 \mathrm{~g} \mathrm{ha}^{-1}$ de glyphosate; 4 - eucalipto consorciado com braquiária que recebeu $720 \mathrm{~g} \mathrm{ha}^{-1}$ de glyphosate; 5 - eucalipto consorciado com braquiária que recebeu $1.440 \mathrm{~g} \mathrm{ha}^{-1}$ de glyphosate; e 6 - eucalipto consorciado com braquiária que recebeu $2.880 \mathrm{~g} \mathrm{ha}^{-1} \mathrm{de}$ glyphosate.

A formulação de glyphosate utilizada foi o Roundup CS (sal de isopropilamina), que foi aplicado sobre as plantas de braquiária nos tratamentos 4,5 e 6 . O tratamento 2 recebeu a aplicação do glyphosate diretamente no solo, utilizando-se pulverizador costal de precisão, propelido a gás carbônico, munido de barra com dois bicos tipo leque TT110.02, operando a $250 \mathrm{KPa}$ de pressão e com volume de calda correspondente a $200 \mathrm{~L} \mathrm{ha}^{-1}$; a muda de eucalipto foi totalmente protegida com um plástico, evitando, assim, o seu contato com a calda herbicida pulverizada. Depois da aplicação do glyphosate, as partes aéreas das mudas de eucalipto permaneceram por 10 horas isoladas das plantas de braquiária, por meio de uma tela de náilon branca. No tratamento 3 , plantas de braquiária, cultivadas em vasos por 30 dias, receberam a pulverização de calda com $1.440 \mathrm{~g} \mathrm{ha}^{-1}$ de glyphosate. Aos $7 \mathrm{DAA}$, a parte aérea das plantas de braquiária foram cortadas rente ao solo e colocadas sobre os vasos de eucalipto, no mesmo dia da aplicação dos demais tratamentos. Na época da aplicação dos tratamentos as plantas de eucalipto apresentavam aproximadamente $50 \mathrm{~cm}$ de altura.
Aos 7 e 14 dias após a aplicação (DAA) foi feita análise visual da eficácia do herbicida no controle da braquiária, avaliando a intoxicação em relação à testemunha, em que 0\% corresponde à ausência de sintomas visiveis e $100 \%$ à morte das plantas (Frans, 1972). Avaliações referentes a altura das plantas (região entre o coleto e o ápice da planta), diâmetro do caule a $1 \mathrm{~cm}$ de altura do solo e biomassa seca da parte aérea foram realizadas aos 18 DAA. Nesta mesma data foram feitas coletas de solo na camada de 1 a $10 \mathrm{~cm}$ de profundidade de cada vaso, sendo as amostras acondicionadas em sacos plásticos, fechados frouxamente, para possibilitar a respiração dos microrganismos, mantidos à temperatura de $4{ }^{\circ} \mathrm{C}$ por 15 dias.

Para quantificação da respiração microbiana, as amostras foram deixadas em temperatura ambiente, sendo, em seguida, peneiradas em malha de $2 \mathrm{~mm}$, determinandose posteriormente o peso seco e a capacidade de campo. De cada amostra, 100 g tiveram sua umidade ajustada para $60 \%$ da capacidade de campo, sendo colocados em potes de plástico de capacidade de $2 \mathrm{~L}$, com tampa. Os potes foram acrescidos de um copo plástico $(50 \mathrm{~mL})$ contendo $20 \mathrm{~mL}$ de hidróxido de sódio $(\mathrm{NaOH})$ $1,0 \mathrm{~mol} \mathrm{~L}^{-1}$, sendo a tampa posteriormente fechada, evitando a troca de ar entre o pote e o ambiente.

O dióxido de carbono desprendido foi amostrado aos 1, 3, 6, 10, 15 e 30 dias após a incubação do solo, substituindo o copo com a solução de $\mathrm{NaOH}$ por outro com $20 \mathrm{~mL}$ da mesma solução. Do $\mathrm{NaOH}$ retirado, tomaramse duas aliquotas de $5 \mathrm{~mL}$, adicionadas em erlenmeyer de $125 \mathrm{~mL}$ contendo $5 \mathrm{~mL}$ de cloreto de bário $\left(\mathrm{BaCl}_{2}\right) 0,5 \mathrm{~mol} \mathrm{~L}^{-1}$, para precipitar todo o $\mathrm{CO}_{2}$ reagido com o $\mathrm{NaOH}$, e três gotas de fenolftaleína como indicador, sendo a mistura titulada com $\mathrm{HCl} 0,5 \mathrm{~mol} \mathrm{~L}^{-1}$ até a viragem, anotando-se o volume gasto.

O mesmo procedimento descrito anteriormente foi utilizado para testemunha sem adição de solo (branco), a fim de determinar a quantidade de $\mathrm{CO}_{2}$ desprendido devido à atividade microbiana, calculada pela seguinte fórmula:

$$
\begin{gathered}
\mathrm{mg} \mathrm{CO} 100 \mathrm{~g}^{-1} \text { de solo }=\left[\left(\mathrm{mL} \mathrm{HCl}_{\text {gasto }} \text { branco }\right)\right. \\
\left.-\left(\mathrm{mL} \mathrm{HCl}_{\text {gasto }} \text { tratamento }\right)\right] \times \mathrm{N} \mathrm{X} 22 \times 4
\end{gathered}
$$

Planta Daninha, Viçosa-MG, v. 23, n. 1, p. 143-152, 2005 
em que o $\mathrm{N}$ é a normalidade do $\mathrm{HCl}$ utilizado na titulação.

Os dados coletados foram submetidos à análise estatística pelo programa SAEG, sendo ajustadas curvas de regressão do $\mathrm{CO}_{2}$ liberado em função dos dias após a incubação do solo.

\section{RESULTADOS E DISCUSSÃO}

\section{Ensaio em solução nutritiva}

Aos sete dias após aplicação (DAA) do glyphosate, todos os tratamentos com o herbicida proporcionaram controle acima de $85 \%$ da braquiária. Aos 15 DAA, o glyphosate apresentou controle acima de 95\% nas plantas de braquiária, que apresentavam raízes com coloração amarronzada, indicando a necrose de tecidos.

Não houve variação na altura, no diâmetro e na biomassa seca da raiz e parte aérea das plantas de eucalipto $(\mathrm{p}>0,05)$. Visualmente, não foi constatada a presença de sintomas de toxidez nas mudas de eucalipto durante a condução do experimento, o que não confirma se houve ou não exsudação do glyphosate pela braquiária. Esses resultados sugerem que as quantidades do herbicida liberadas na solução nutritiva via exsudação podem ter sido muito baixas para provocarem injúrias no eucalipto, ou que a braquiária não libera o glyphosate via exsudação radicular.

Os resultados permitem afirmar que o herbicida exsudado pelas raizes de plantas daninhas tratadas não é a causa das injúrias observadas no campo em plantas de eucalipto. Provavelmente, as injúrias observadas em áreas onde o glyphosate é usado para controle de plantas daninhas em eucalipto sejam causadas, em sua grande maioria, pela deriva. Segundo Tuffi Santos et al. (2004), plantas de eucalipto expostas a deriva simulada com doses iguais a 43,2 $\mathrm{g}^{-1} \mathrm{a}^{-1}$ de e.a. de glyphosate apresentam alterações em sua morfoanatomia e redução no crescimento.

\section{Ensaio no solo}

Assim como na solução nutritiva, aos 7 DAA do glyphosate todos os tratamentos com herbicida proporcionaram controle acima de $85 \%$, chegando aos 15 DAA com a morte da braquiária.

Planta Daninha, Viçosa-MG, v. 23, n. 1, p. 143-152, 2005
Visualmente, não foi constatada a presença de sintomas de intoxicação nas mudas de eucalipto durante a condução do experimento. Os resultados observados são esperados, uma vez que o glyphosate é rapidamente adsorvido pelos colóides do solo (Rodrigues \& Almeida, 1998), não ficando disponível na solução do solo para absorção pelas plantas. No dois solos, o glyphosate pode ter sido exsudado no solo e absorvido pelas plantas de eucalipto, mas em quantidades inferiores àquelas necessárias para causar injúrias na planta.

Rodrigues et al. (1982), trabalhando com exsudação radicular do glyphosate em dois solos arenosos, 86 e $56 \%$ de areia, comprovaram a exsudação radicular de ${ }^{14} \mathrm{C}$ - glyphosate por plantas de trigo tratadas com este herbicida. No mesmo experimento, os mesmos autores descrevem a absorção do ${ }^{14} \mathrm{C}$ - glyphosate pelas raízes de milho cultivadas ao lado das plantas de trigo; o herbicida absorvido foi translocado para todas as partes da planta, apesar de as maiores concentrações serem encontradas nas raizes. Entretanto, o ${ }^{14} \mathrm{C}$ - glyphosate absorvido não causou toxidez nas plantas de milho, não afetando a altura das plantas nem a biomassa seca. Os resultados dos ensaios com deriva do glyphosate em eucalipto (Tuffi Santos et al., 2004) confirmam que esta espécie é mais tolerante ao glyphosate que o milho (Magalhães et al., 2001).

A biomassa seca e o diâmetro da parte aérea das plantas de eucalipto diferiram estatisticamente entre os tratamentos pelo teste $F(p<0,05)$, não sendo observada diferença na altura das plantas. Não houve diferença pelo teste $\mathrm{F}(\mathrm{p}<0,05)$ para as características avaliadas entre os dois solos e para interação solo-tratamentos. Tanto no solo arenoso quanto no argiloso, os tratamentos compostos de plantas de eucaliptos cultivadas isoladamente obtiveram os maiores valores de diâmetro do caule e da biomassa seca (Tabela 2), o que pode ser explicado pela competição imposta pelas plantas de braquiária nos demais tratamentos em consórcio braquiária + eucalipto.

As análises dos resultados da respiração microbiana indicaram diferença estatística entre as variáveis solo e época de avaliação pelo teste $F(p<0,05)$, não sendo significativas para os manejos empregados e nas interações 
$(p>0,05)$. Na Figura 1 encontram-se as regressões, para os diferentes tratamentos, nos dois solos, da quantidade de $\mathrm{CO}_{2}$ liberada ( $m g \mathrm{CO}_{2} 100 \mathrm{~g}^{-1}$ de solo) em função da época de avaliação (dias).

Após a incubação, em geral, houve maior respiração microbiana no solo arenoso que no argiloso. Solos arenosos apresentam maior porcentagem de macroporos, o que leva à maior aeração, favorecendo a atividade da biota aeróbica desses solos. Souza et al. (1999), trabalhando com solo argiloso e arenoso, relatam maior respiração microbiana neste último, principalmente com $100 \%$ de umidade. Segundo Pivetz \& Steenhuis (1995), os macroporos podem facilitar a degradação microbiana por causa da maior disponibilidade de oxigênio, nutrientes e substratos orgânicos e das maiores populações de microrganismos.

Assis Júnior et al. (2003), trabalhando com atividade microbiana no solo em diferentes sistemas de uso da terra, relatam maior atividade da microbiota, no $20^{\circ}$ dia após a incubação, nos sistemas mata nativa e pastagem em monocultura e consorciada com eucalipto, quando comparados com áreas desmatadas, eucalipto solteiro, eucalipto com sub-bosque, eucalipto em consórcio com milho, eucalipto em consórcio com soja e com os monocultivos de soja e milho. Della Bruna et al. (1991) encontraram maior atividade sob a mata nativa do que em reflorestamento com eucalipto, observando que solos sob eucalipto apresentam menor teor de bases e maior relação carbono/ nitrogênio, o que contribui para menor atividade microbiana nesses sistemas.

Nos tratamentos que receberam a aplicação do glyphosate diretamente no solo ou na braquiária, apesar de não serem estatisticamente significativos, nota-se uma maior atividade microbiana em valores absolutos com o aumento das doses do herbicida, principalmente no solo arenoso. Esse resultado indica a utilização do glyphosate como fonte de carbono pelos microrganismos do solo, o que corrobora os resultados de Sprankle et al. (1975) e Souza et al. (1999). Os primeiros autores (1975) consideram a ação dos microrganismos o principal fator responsável pela degradação do glyphosate no solo. Segundo Heinonen-Tanski (1989), a degradação está diretamente relacionada ao $\mathrm{CO}_{2}$ liberado do solo.

As concentrações de glyphosate presentes no solo arenoso podem estar mais disponiveis para a biodegradação do que no solo argiloso.

Tabela 2 - Valores médios do crescimento de plantas de eucalipto submetidas a diferentes manejos com herbicida glyphosate

\begin{tabular}{|c|c|c|c|c|}
\hline Solo & Manejo & $\begin{array}{l}\text { Altura } \\
(\mathrm{cm})\end{array}$ & $\begin{array}{l}\text { Diâmetro } \\
\text { (cm) }\end{array}$ & $\begin{array}{c}\text { Biomassa } \\
\text { Seca }(\mathrm{g})\end{array}$ \\
\hline \multirow{7}{*}{$\begin{array}{l}0 \\
\stackrel{0}{0} \\
\stackrel{0}{0} \\
\stackrel{2}{Z}\end{array}$} & Eucalipto consorciado com braquiária & $90,83 \mathrm{a}$ & $1,00 \mathrm{~b}$ & $44,15 \mathrm{~b}$ \\
\hline & Eucalipto monocultivo $+1.440 \mathrm{~g} \mathrm{ha}^{-1}$ de glyphosate no solo & $87,83 \mathrm{a}$ & $1,28 \mathrm{a}$ & $73,53 \mathrm{a}$ \\
\hline & Eucalipto + palha de braquiária tratada com $1.440 \mathrm{~g} \mathrm{ha}^{-1}$ de glyphosate & $85,00 \mathrm{a}$ & $1,31 \mathrm{a}$ & $58,53 \mathrm{ab}$ \\
\hline & Eucalipto consorciado com braquiária $+720 \mathrm{~g} \mathrm{ha}^{-1}$ de glyphosate & $86,00 \mathrm{a}$ & $1,07 \mathrm{~b}$ & $45,60 \mathrm{~b}$ \\
\hline & Eucalipto consorciado com braquiária $+1.440 \mathrm{~g} \mathrm{ha}^{-1}$ de glyphosate & $86,02 \mathrm{a}$ & $1,10 \mathrm{~b}$ & $45,82 \mathrm{~b}$ \\
\hline & Eucalipto consorciado com braquiária $+2.880 \mathrm{~g} \mathrm{ha}^{-1}$ de glyphosate & $90,16 \mathrm{a}$ & $1,09 \mathrm{~b}$ & $44,18 \mathrm{~b}$ \\
\hline & $\mathrm{CV}(\%)$ & 6,51 & 10,38 & 18,21 \\
\hline \multirow{7}{*}{$\begin{array}{l}\stackrel{0}{0} \\
\stackrel{0}{0} \\
\stackrel{50}{4}\end{array}$} & Eucalipto consorciado com braquiária & $87,17 \mathrm{a}$ & $1,09 \mathrm{bc}$ & $51,25 \mathrm{~b}$ \\
\hline & Eucalipto sem braquiária $+1.440 \mathrm{~g} \mathrm{ha}^{-1}$ de glyphosate no solo & $91,67 \mathrm{a}$ & $1,27 \mathrm{ab}$ & $84,78 \mathrm{a}$ \\
\hline & Eucalipto + palha de braquiária tratada com $1.440 \mathrm{~g} \mathrm{ha}^{-1}$ de glyphosate & $93,17 \mathrm{a}$ & $1,33 \mathrm{a}$ & $79,10 \mathrm{a}$ \\
\hline & Eucalipto consorciado com braquiária $+720 \mathrm{~g} \mathrm{ha}^{-1}$ de glyphosate & $81,68 \mathrm{a}$ & $1,08 \mathrm{c}$ & $43,42 \mathrm{~b}$ \\
\hline & Eucalipto consorciado com braquiária $+1.440 \mathrm{~g} \mathrm{ha}^{-1}$ de glyphosate & $85,50 \mathrm{a}$ & $1,13 \mathrm{bc}$ & $51,37 \mathrm{~b}$ \\
\hline & Eucalipto consorciado com braquiária $+2.880 \mathrm{~g} \mathrm{ha}^{-1}$ de glyphosate & $87,67 \mathrm{a}$ & $1,14 \mathrm{bc}$ & $53,15 \mathrm{~b}$ \\
\hline & $\mathrm{CV}(\%)$ & 7,59 & 8,92 & 12,83 \\
\hline
\end{tabular}

Médias seguidas pelas mesmas letras nas colunas não diferem entre si pelo teste de Tukey a $5 \%$ de probabilidade. 
De acordo com Souza et al. (1999), a interação entre microrganismos, substrato e constituintes do solo pode alterar a biodegradação dos herbicidas, sendo maior ou menor conforme com a capacidade adsortiva do solo. Assim, a adsorção pode reduzir as concentrações do herbicida na solução do solo, de forma a não

Eucalipto consorciado com braquiária

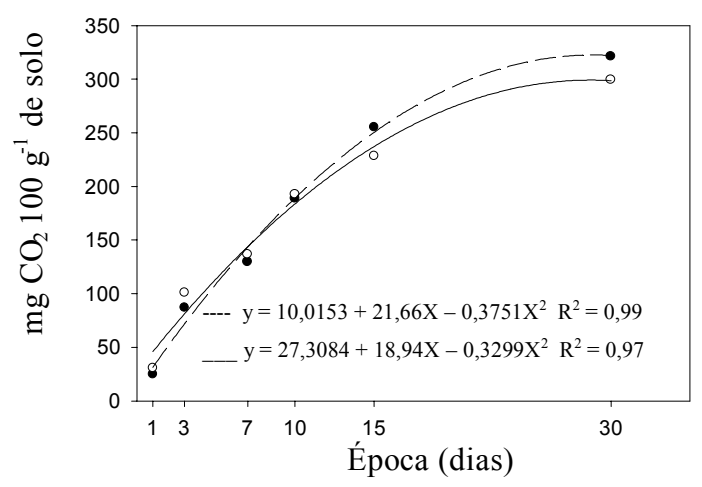

Eucalipto + braquiária cortada com

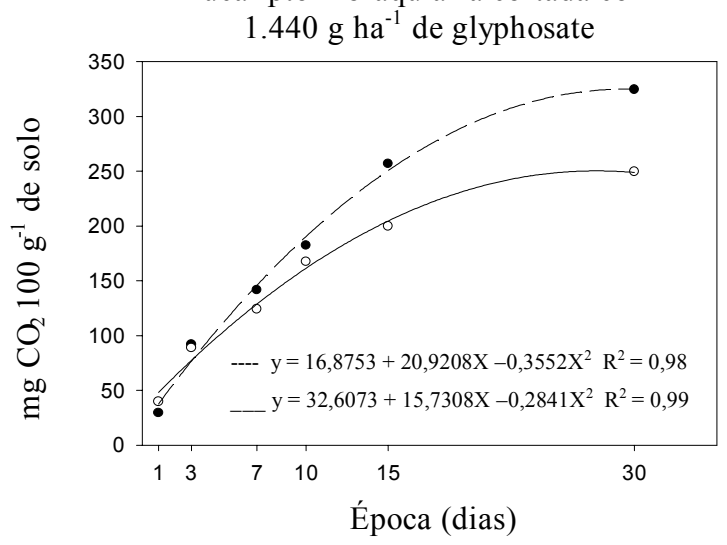

Eucalipto + braquiária plantada com

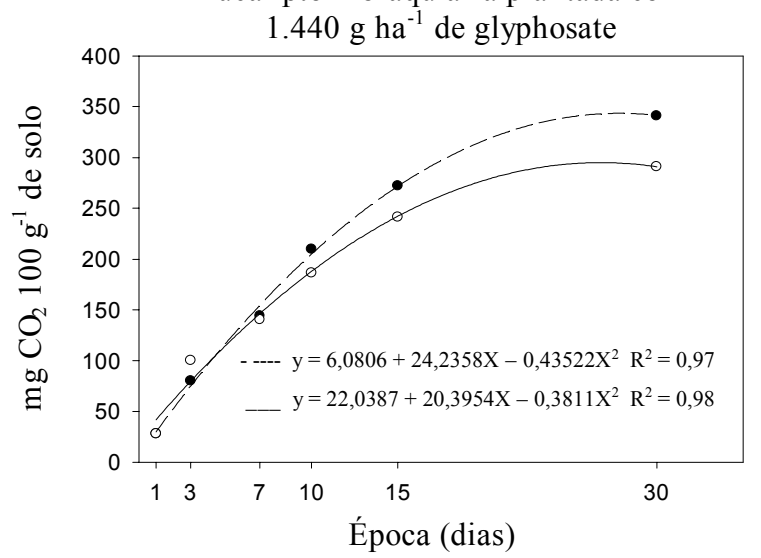

induzir a sua biodegradação (Madsen, 1991) ou a níveis não-tóxicos aos microrganismos, o que resultaria no aumento da degradação dessas moléculas (Van Loosdrecht et al., 1990), o que pode explicar a variação nas quantidades de $\mathrm{CO}_{2}$ liberadas entre os solos arenoso e argiloso.

\section{Eucalipto $+1.440 \mathrm{~g} \mathrm{ha}^{-1}$ de glyphosate no} solo

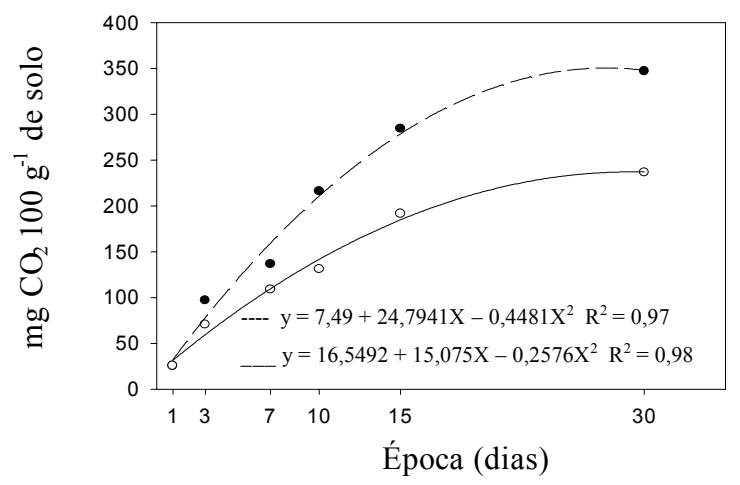

Eucalipto + braquiária plantada com $720 \mathrm{~g} \mathrm{ha}^{-1}$ de glyphosate

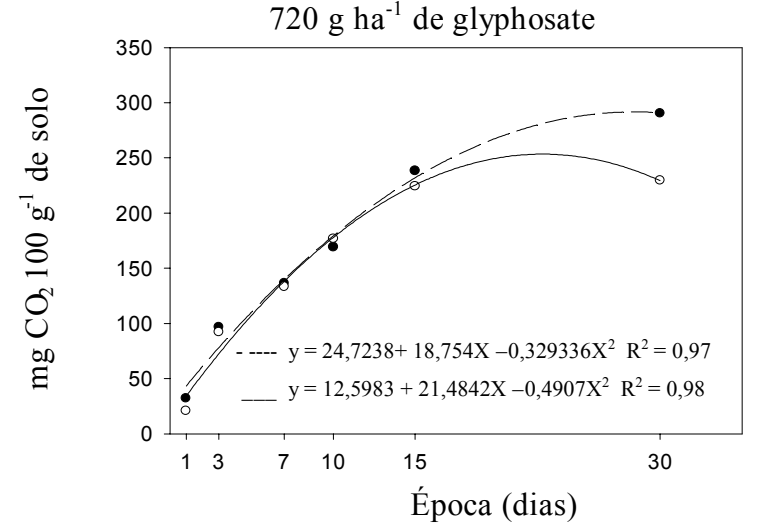

Eucalipto + braquiária plantada com

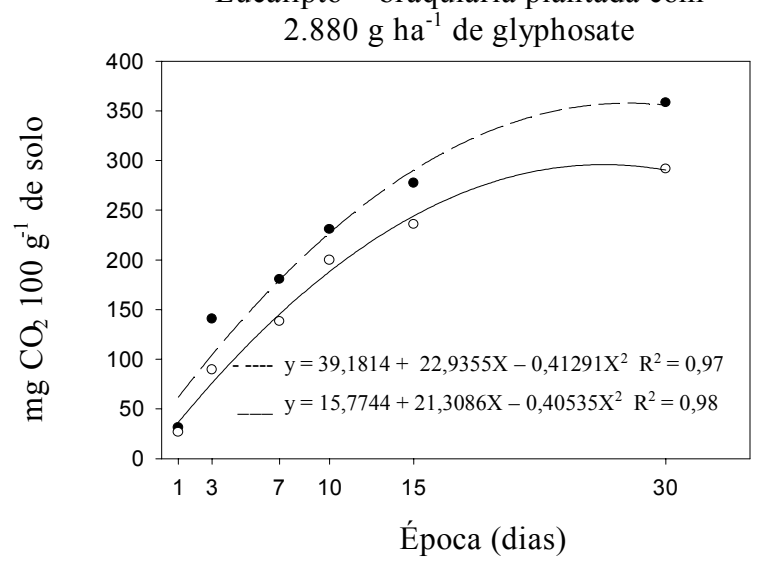

Figura 1 - Quantidade de $\mathrm{CO}_{2}$ liberada pela atividade microbiana nos solos arenoso e argiloso nas diferentes combinações de manejo com glyphosate, na cultura do eucalipto ( - solo arenoso; ---- solo argiloso). 
A presença do glyphosate nos solos florestais pode favorecer a microbiota, que consegue degradar este herbicida e, por outro lado, suprimir outros microrganismos, inclusive os benéficos, alterando assim o equilíbrio da microfauna desses ambientes. Paula Júnior \& Zambolim (1994) relatam que o glyphosate reduz a colonização das raízes de eucalipto por micorrizas. Segundo Dodd \& Jeffries (1989), é muito provável que o uso freqüente de herbicidas em uma determinada área possa causar inibição seletiva de fungos micorrízicos no campo.

Os trabalhos realizados permitem concluir que não houve sintomas de toxidez nas plantas de eucalipto cultivadas em sistema hidropônico ou no solo, indicando que, se houve exsudação do glyphosate, ela ocorreu em concentrações inferiores às necessárias para provocar injúrias no eucalipto. Logo, o herbicida exsudado pelas raízes de plantas daninhas tratadas não é a causa das injúrias observadas no campo em plantas de eucalipto. No entanto, o uso do glyphosate afetou a atividade microbiana, que foi maior no solo arenoso, principalmente com o aumento das doses aplicadas nas plantas de braquiária.

\section{LITERATURA CITADA}

ASSIS JUNIOR, S. L. et al. Atividade microbiana do solo em sistemas agroflorestais, monoculturas, mata natural e área desmatada. R. Árvore, v. 27, n. 1, p. 35-41, 2003.

BEIGEL C.; CHARNAY, M. P.; BARRIUSO, E. Degradation of formulated and informulated triticonazole fungicide in soil: effect of application rate. Soil Biol. Biochem., v. 31, p. 525-534, 1999.

CLARK, R. B. Characterization of phosphatase of intact maize roots. J. Agric. Food Chem., v. 23, n. 3, p. 458 460, 1975.

COLE, D. J.; CASELEY, J. C.; DODGE, A. D. Influence of glyphosate on selected plant process. Weed Res., v. 23, p. 173-183, 1983.

COUPLAND, D.; CASELEY, J. C. Presence of ${ }^{14} \mathrm{C}$ activity in root exsudates and guttation fluid from Agropyron repens treated with ${ }^{14} \mathrm{C}$-labelled glyphosate. New Phytol., v. 83, n. 1, p. 17-22, 1979.

DELLA BRUNA, E. et al. Atividade da microbiota de solos adicionados de serapilheira de eucalipto e de nutrientes.

R. Bras. Ci. Solo, v. 15, p. 15-20, 1991.
DODD, J. C.; JEFFRIES, P. Effects of herbicides on tree vesicular-arbuscular fungi associated with winter wheat (Triticum aestivum L.). Biol. Fertil. Soils, v. 7, p. 113-119, 1989.

FITES, R. C.; SLIFE, F. W.; HANSON, J. B. Translocation and metabolism of radioactive 2,4-D in jimsonweed. Weeds, v. 12, n. 3, p. 180-183, 1964.

FRANS, R. E. Measuring plant responses. In: WILKINSON, R. E. (Ed.) Research methods in weed science. [S.1.]: Southern Weed Science Society, 1972. p. 28-41.

GHINI, R.; LIGO, M. A. V.; HERMES, L. C. Efeito de herbicidas na biomassa microbiana de solos de arroz irrigado. R. Ecos., v. 22, p. 97-101, 1997.

GUBBIGA, N. G.; WORSHAM, A. D.; CORBIN, F. T. Root/rhizome exudation of nicosulfuron from treated johnsongrass (Sorghum halepense) and possible implications for corn (Zea mays). Weed Sci., v. 44, n. 3, p. 455-460, 1996.

HEINONEN-TANSKI, $\mathrm{H}$. The effect of temperature and liming on the degradation of glyphosate in two arctic forest soils. Soil Biol. Biochem., v. 21, n. 2, p. 313-317, 1989.

LINDER, P. J.; CRAIG JR, J. C.; WALTON, T. R. Movement of ${ }^{14} \mathrm{C}$-tagged alpha-methoxyphenylacetic acid out of roots. Plant Physiol., v. 32, n. 6, p. 572- 575, 1957.

LINDER, P. J.; MITCHELL, J. W.; FREEMAN, G. D. Persistence and translocation of exogenous regulating compounds that exude from roots. J. Agric. Food Chem., v. 12 , n. 5, p. 437-438, 1964.

MADSEN, E. L. Determining in situ biodegradation: facts and challenges. Environ. Sci. Technol., v. 25, n. 1, p. 1663$1673,1991$.

MAGALHÃES, P. C. et al. Efeito de doses reduzidas de glyphosate e paraquat simulando deriva na cultura do milho. Planta Daninha, v. 19, n. 2, p. 247-253, 2001.

PAULA JUNIOR, T. Z.; ZAMBOLIM, L. Efeito de fungicidas e de herbicidas sobre a micorrização de Eucalyptus grandis por Glomus etunicatum. Fitopatol. Bras., v. 19, n. 2, p. 173-177, 1994.

PIVETZ, B. E.; STEENHUIS, T. S. Soil matrix and macropore biodegradation of 2,4-D. J. Environ. Quality, v. 24, n. 4, p. 564-570, 1995.

RIZZARD, M. A. et al. Ação dos herbicidas sobre o mecanismo de defesa das plantas aos patógenos. Ci. Rural, v. 33, n. 5, p. 957-965, 2003.

Planta Daninha, Viçosa-MG, v. 23, n. 1, p. 143-152, 2005 
RODRIGUES, J. J. V.; WORSHAM, A. D.; CORBIN, F. T. Exudation of glyphosate from wheat (Triticum aestivum) plants and its effects on interplanted corn (Zea mays) and soybeans (Glycine max). Weed Sci., v. 30, p. 316-320, 1982.

RODRIGUES, B. N.; ALMEIDA, F. S. Guia de herbicidas. 4.ed. Londrina: Edição dos autores, 1998. $648 \mathrm{p}$.

RUEPPEL, M. L. et al. Metabolism and degradation of glyphosate in soil and water. J. Agric. Food Chem., v. 25, v. 3, p. 517-528, 1977.

SILVA, C. M. M. et al. Root exudation of imazapyr by eucalypt, cultivated in soil. Planta Daninha, v. 22, n. 1, p. 109-116, 2004

SMITH, W. H. Character and significance of forest tree root exudates. Ecology, v. 57, n. 2, p. 324-331, 1976.
SPRANKLE, P.; MEGGITT, W. F.; PENNER, D.

Adsorption, mobility and microbial degradation of glyphosate in the soil. Weed Res., v. 23, n. 3, p. 229-234, 1975.

SOUZA, A. P. et al. Respiração microbiana do solo sob doses de glyphosate e de imazapyr. Planta Daninha, v. 17, n. 3, p. 387-398, 1999.

TOLEDO, R. E. B. et al. Faixas de controle de plantas daninhas e seus reflexos no crescimento de plantas de eucalipto. Sci. For., v. 64, p. 78-92, 2003.

TUFFI SANTOS, L. D. et al. Simulação de deriva do glyphosate em eucalipto. In: CONGRESSO BRASILEIRO DA CIÊNCIA DAS PLANTAS DANINHAS, 24., 2004, São Pedro. Resumos Expandidos... São Pedro: Sociedade Brasileira da Ciência das Plantas Daninhas, 2004. CD-ROM.

Van LOOSDRECHT, M. C. M.; LYKLEMA, J.; NORDE, W. Influence of interfaces on microbial activity. Microbiol. Rev., v. 54, n. 1, p. 75-87, 1990. 